\title{
SIMWAL: A structural-functional model simulating single walnut tree growth in response to climate and pruning
}

\author{
Philippe Balandier, ${ }^{\mathrm{a},}$, André Lacointe ${ }^{\mathrm{b}}, \mathrm{Xavier} \mathrm{Le} \mathrm{Roux}^{\mathrm{b}}$, Hervé Sinoquet ${ }^{\mathrm{b}}$, \\ Pierre Cruiziat ${ }^{\mathrm{b}}$ and Séverine Le Dizès ${ }^{\mathrm{a}, \mathrm{b}}$ \\ ${ }^{a}$ Cemagref, Unité de Recherche Forêt et Agroforesterie, Groupement de Clermont-Ferrand, 24 avenue des Landais, \\ BP. 50085, 63172 Aubière Cedex, France \\ ${ }^{\mathrm{b}}$ UMR PIAF, INRA - Université Blaise Pascal, Domaine de Crouelle, 234 avenue du Brezet, \\ 63039 Clermont-Ferrand Cedex 02, France
}

(Received 8 February 1999; accepted 28 June 1999)

\begin{abstract}
SIMWAL (SIMulated WALnut) is a structural-functional tree model developed for single young walnut tree (Juglans sp.). It simulates the 3D structure dynamics of the tree, and biomass partitioning among its different organs, for a period ranging from a few months to several years, according to climatic conditions (temperature, radiation and air $\mathrm{CO}_{2}$ concentration) and pruning. The aerial part of the tree is represented by axes split into growth units, inter-nodes, buds and leaves. The root system is described very coarsely by three compartments (taproot, coarse root and fine root). Only carbon-related physiological processes, i.e., radiation interception, photosynthesis, respiration, photosynthate allocation, and reserve storage and mobilisation are taken into account. Water and mineral nutrients are assumed to be optimal. We describe the model, and present preliminary tests of its ability to simulate tree architecture dynamics and carbon balance compared with field observations. Data requirements, and limits and improvements of the model are discussed.
\end{abstract}

structure / function / model / Juglans / pruning

Résumé - SIMWAL : un modèle d'arbre structure-fonction simulant la croissance d'un noyer en fonction du climat et de la taille. SIMWAL est un modèle d'arbre structure-fonction développé pour le jeune noyer (Juglans sp.). Il simule l'évolution de la structure 3D de l'arbre et la répartition de la biomasse entre ses différents organes, pour des périodes allant de quelques mois à quelques années, en fonction des conditions climatiques (température, radiation, concentration dans l'air du $\mathrm{CO}_{2}$ ) et des opérations de taille. La partie aérienne de l'arbre est représentée par des axes, eux-mêmes divisés en unités de croissance, entrenœuds, bourgeons et feuilles. Le système racinaire est plus grossièrement décrit en trois compartiments : pivot, racines moyennes et racines fines. Seuls les processus physiologiques relatifs au carbone sont pris en compte : interception lumineuse, photosynthèse, respiration, répartition carbonée, et stockage et mobilisation des réserves. L'eau et les éléments minéraux sont considérés à l'optimum. Nous décrivons en détail le modèle et présentons quelques tests préliminaires visant à vérifier sa capacité à simuler l'évolution de l'architecture d'un arbre et son bilan de carbone en comparaison à des observations de terrain. Le manque de certaines connaissances, les limites et les améliorations possibles du modèle sont discutés.

structure / fonction / modèle / Juglans / taille

* Correspondence and reprints

Tel. 04734406 23; Fax. 04734406 98; e-mail: philippe.balandier@cemagref.fr 


\section{INTRODUCTION}

In the last decades, modelling has become a powerful tool for studying and understanding plant growth and other processes. This is especially true for trees because their decade- or century-long life span make it very difficult to run relevant experiments that would be required in each different situation [13]. Models can offer a conceptual framework for research. Gary et al. [23] compare them to puzzles where missing pieces can be identified, various persons or groups can mobilise their different skills in cooperative projects, and different levels of organisation can be considered.

According to the kind of knowledge used (botanical concepts, statistical relationships, physiological processes), the scale (from tree organs [6] up to single trees or whole stands, e.g., [17]), and the targets (prediction of total dry matter production, photosynthate partitioning, or tree architecture dynamics), many different tree models have been proposed (for reviews see [7, 24]).

In this last decade, the general tendancy has been to (i) include physiological processes in models (processbased models), and (ii) work at individual or organ scale. Physiological processes are essential in accounting for the effects of climate and soil factors for simulating growth in many different environments [34, 44, 59]. Indeed, if changes in future management regimes, human impact on the atmosphere (climate change, atmospheric chemistry) and/or changes in soil fertility alter future growth conditions, the prediction of tree growth using classical yield tables (volume-age curves, height-age curves, yield tables) will be inaccurate [44, 60]. Another factor is the increasing complexity of the stand structure being studied. While it is possible to work at the stand level with a monospecific, regular and evenly-aged stand, this is more difficult with irregular stands that mix one or more species of different sizes, shapes and ages [7, 13]. The individual tree growth approach provides the best representation of observed tree growth distribution in a stand in most cases in comparison with distribution-prediction or stand table projection approaches [32]. In addition, in many competition indices, individual tree characteristics are used (crown length, horizontal extension, etc.), which leads de facto to the use of a tree scale in modelling [11].

More recently, "mixed models" or "structural-functional models" (SFMs) have been developed that combine architectural with mechanistic models [15, 57]. The aim is to achieve a realistic 3D growth prediction based on physiological processes. However, just including physiological processes in models often does not improve their accuracy if tree architecture or structure is not described to some degree [57]. For instance simulating the process of light interception requires an adequate description of the tree crown $[11,58]$. Similarly water relationships are grounded on the tree hydraulic architecture [33], possibly including the root system [19]. An appropriate description of crown development also proves essential to simulate intensive silvicultural practices [14].

Using SFMs allows plant growth to be simulated taking into account competition for resource capture between organs at the plant level or between individual plants at the plot level [22]. Because wood quality is strongly correlated with both tree growth characteristics and architecture (type of axis, angle of insertion, axis reorientation, internal constraints, etc.), predicting wood quality requires the model to interconnect tree structure and growth processes [16, 27, 64]. Normally, by construction, SFMs should be able to take climate, soil characteristics and cultural practices into account. Using a "structural-functional tree model" (SFTM) is consequently useful for simulating tree response to shoot pruning, because pruning modifies architecture, leaf area and also photosynthetic processes [4, 24, 50]. Moreover, tree response to pruning is not simply a decrease in photosynthetic capacities; growth correlations among organs within the tree are also modified [4]. Progress in data processing has resulted in the development of complex SFTMs such as LIGNUM [48, 49] and ECOPHYS [52]. LIGNUM simulates the 3D growth of a softwood with a simple architecture according to light climate, with a time step of one year. ECOPHYS runs with an hourly step and predicts the 3D growth of young clones (first growth year) of poplar according to climate. Results are very accurate but the large number of parameters used in the model restricts its application to other species. The model of Génard et al. [24] is designed to simulate the effect of pruning on a peach tree in its first year of growth. It takes into account the growth correlations among organs in the tree through root-shoot interactions. The latter two models simulate tree growth only during one year and consequently do not allow to simulate the effects of inter-annual climatic variations.

None of those models fully met our objectives. We wanted to design a model that would (i) simulate tree growth for several years, (ii) use a $3 \mathrm{D}$ realistic description of the tree at the organ scale to simulate tree response to local microclimate modifications, (iii) simulate the effects of cultural practices, particularly pruning, and (iv) use only variables that have a physiological meaning. This paper describes SIMWAL (SIMulated WALnut), an SFTM developed for single young walnut trees (Juglans sp.) and reports results of preliminary tests of its ability to simulate the 3D structure dynamics and biomass partitioning among organs in relation to climate and pruning. For this first version, only carbon processes 
are taken into account, nitrogen and water being taken as optimal. Only results of one year of simulation are described in this paper to check the model consistency in this first step of model development. A next paper will give results on several years.

\section{MATERIALS AND METHODS}

\subsection{Model description}

\section{General organisation and computer implementation}

Figure 1 shows the schematic organisation of the model. Its inputs are tree data for initial stage (including topological and geometrical characteristics, and parameters for the main processes), climate and soil data (at present air and soil temperatures, radiation, air VPD and air $\mathrm{CO}_{2}$ concentration). The carbon processes taken into account are radiation interception, photosynthesis, respiration, photosynthate allocation, and reserve storage and remobilisation. Radiation interception and photosynthesis are computed hourly to account for the variations in the incident radiation in the crown during the day.

Photosynthate allocation and growth increment are daily based. As these latter processes are less influenced by hourly fluctuations than radiation interception and photosynthesis, computing them on an hourly scale would probably not improve the accuracy of the model.

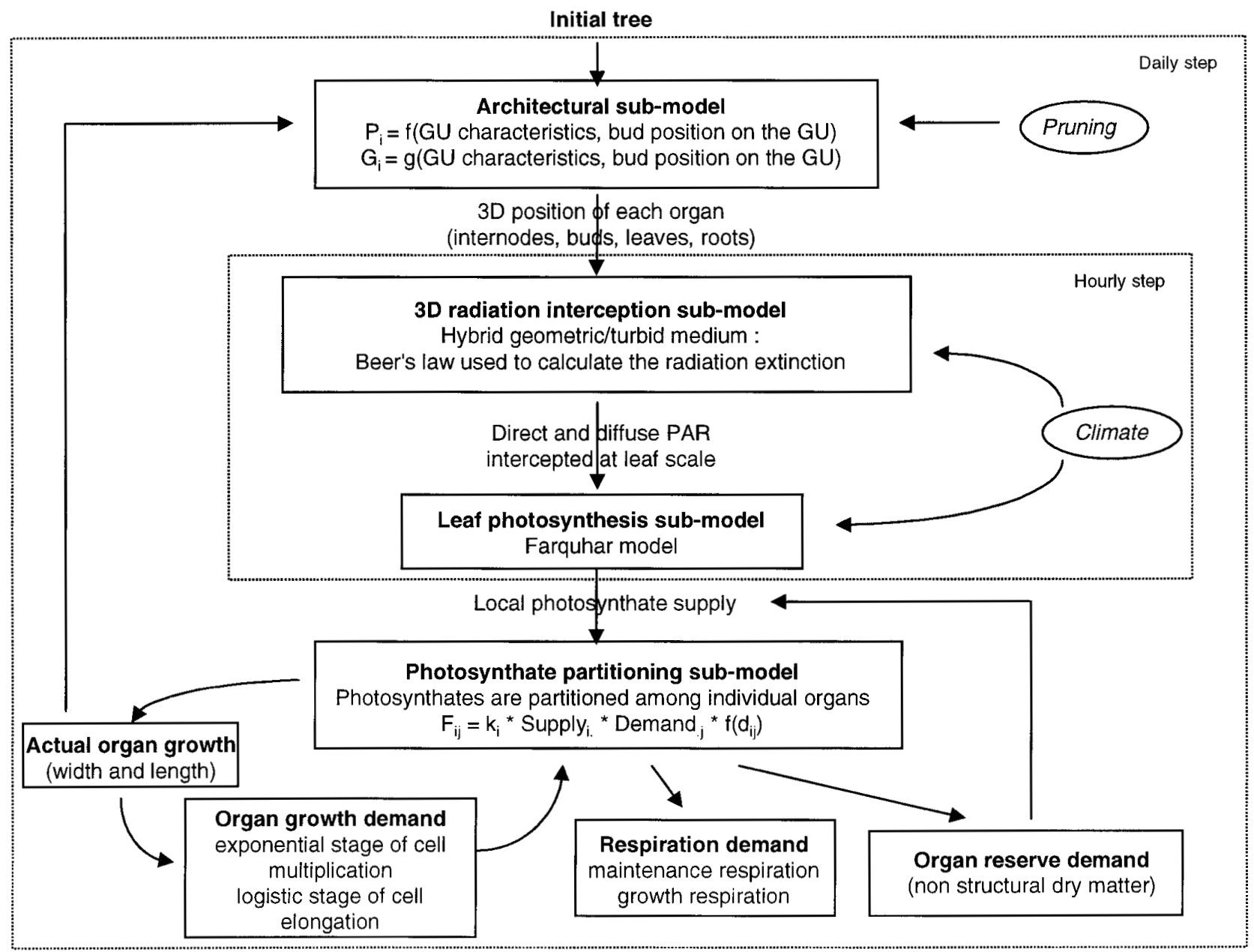

Figure 1. Schematic organisation of the model. $\left(P_{i}\right.$ : budburst probability, $G_{i}$ : growth potentiality, $F_{i j}$ : photosynthate flux between a source $i$ and a sink $j, k_{i}$ : coefficient of matter conservation, $f\left(d_{i j}\right)$ : function modulating the effect of the distance $\left(d_{i j}\right)$ between a source $i$ and a sink $j$ ). 
The model outputs are the daily results of the components of the tree carbon balance (i.e. respiratory losses, structural and non-structural (reserve) dry matter production) and resulting changes in tree structure (number of organs, their dimension, topological and geometrical relationships, etc.).

SIMWAL runs on a Pentium Pro $200 \mathrm{MHz}$ PC with 64 Mo RAM. For details of the computer implementation see $[8,28]$. Tree organs are described as objects with their own features (attributes) and processes coded in a rule-based language (PROLOG II+, PrologIA, Marseille, France). A simulation engine in the heart of the program (growth engine) interacts with the organs attributes, climate parameters and process rules to run the simulation at each time step. A control structure (sce- nario) specifies the sequential order in which the engine considers the different organs in a given time step and with what sets of rules (for details see [38]).

\section{Tree description}

Tree is described according to $[5,15]$. The aboveground part is broken down into axes (trunk, branches, twigs, each with their age and branching order) which are in turn split into growth units (GUs; see figure 2), internodes and nodes bearing a bud and a leaf. Each organ is positioned in the $3 \mathrm{D}$ space by its coordinates and orientation. Thus some tree architectural features such as axis phyllotaxy, angle of axis insertion, etc. are explicitly represented. Two consecutive organs are
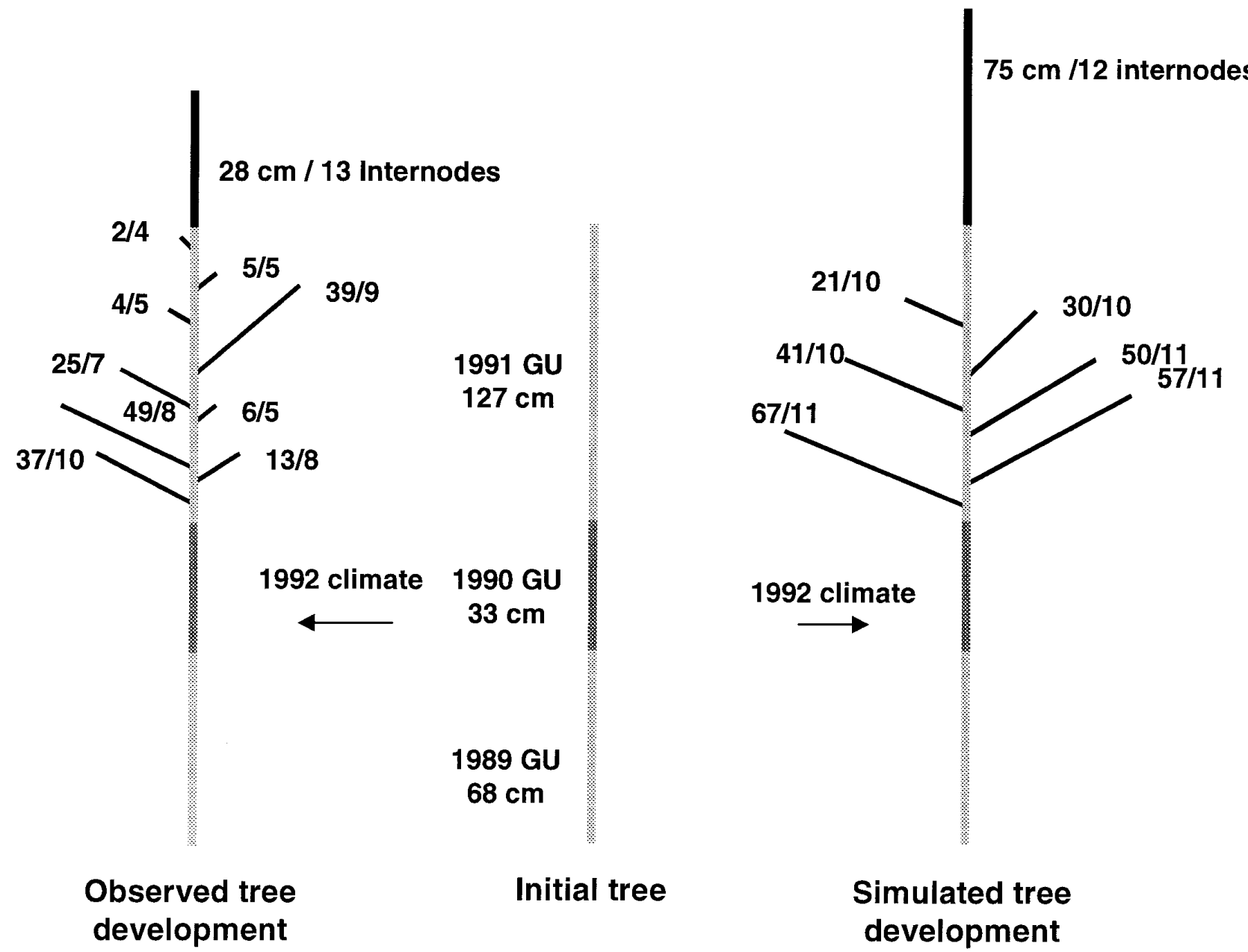

Figure 2. Comparison of the observed and simulated architecture dynamics of a given tree in 1992. The lenght (cm) and the number of internodes are given for each new GU of 1992. 
linked together by topological links (e.g., GU1 bears GU2 and GU2 bears GU3, etc.). Thus the model is able to calculate the topological or metrical distances separating two organs. The root system is described more coarsely as made of three compartments (three cylinders with their diameter and length), namely taproot, coarse root and fine root, to avoid making the model too complicated in this first version. The three compartments are attached at a distance from the root-shoot junction representing the mean distance of attachment of the root type in the root system.

\section{Leaf irradiance}

The light submodel simulates light microclimate at the leaf level to focus on the variation of leaf irradiance within the crown. For this purpose, two approaches were proposed. The first one applies to young trees where shading between leaves is assumed not to occur. In this case, variations in leaf irradiance are due solely to differences in leaf angle (cf. Eqs. (6) and (10)). The second approach addresses larger trees, in which additional variations in leaf irradiance are due to shading effects.

In the case of larger trees, the tree crown is approximated as an ellipsoid as previously proposed by several authors (e.g. [45, 67]). Parameters of the ellipsoid are computed from the spatial co-ordinates $\left(x_{i}, y_{i}, z_{i}\right)$ of leaves $(i=1, \ldots N)$, as they are simulated from the architecture submodel. The ellipsoid equation is given by:

$$
\frac{\left(x-x_{0}\right)^{2}}{a^{2}}+\frac{\left(y-y_{0}\right)^{2}}{b^{2}}+\frac{\left(z-z_{0}\right)^{2}}{c^{2}}=1
$$

where $x_{0}=\left(x_{\min }+x_{\max }\right) / 2, y_{0}=\left(y_{\min }+y_{\max }\right) / 2, z_{0}=\left(z_{\min }\right.$ $\left.+z_{\max }\right) / 2$, and $a=\left(x_{\max }-x_{\min }\right) / 2, b=\left(y_{\max }-y_{\min }\right) / 2$, $c=\left(z_{\max }-z_{\min }\right) / 2$. Minimum and maximum values of $x$, $y$ and $z$ are retrieved from spatial co-ordinates $\left(x_{i}, y_{i}, z_{i}\right)$ of leaves (e.g. $\left.x_{\min }=\operatorname{Min}\left[x_{i}, i=1, \ldots N\right]\right)$. Parameters $a, b$ and $c$ are half axis of the ellipsoid along $X, Y$ and $Z$ axis, respectively. The crown volume $V$ and leaf area density $D$ within the crown can then be written:

$$
\begin{gathered}
V=(4 / 3) \cdot \pi \cdot a \cdot b \cdot c \\
D=\sum_{i=1}^{N} L_{i} / V
\end{gathered}
$$

where $L_{i}$ is the leaf area of leaf $i$. The probability $P_{0 \text { is }}$ that a leaf $i$ is sunlit is computed from Beer's law applied to the sun direction $\Omega_{\mathrm{s}}$ of elevation $H_{\mathrm{s}}$ and azimuth $A_{\mathrm{s}}$.
Assuming a spherical leaf angle distribution, $P_{0 \text { is }}$ can be written:

$$
P_{0 \text { is }}=\exp \left[-D \cdot \frac{z_{\mathrm{e}}-z_{i}}{2 \cdot \sin H_{\mathrm{s}}}\right]
$$

where $z_{\mathrm{e}}$ is the height where a sunbeam reaching leaf $i$ enters the ellipsoid. Altitude $z_{\mathrm{e}}$ is given by the intersection between the ellipsoid envelope and the beam line. The latter is given by:

$$
\frac{x-x_{i}}{\cos H_{\mathrm{s}} \cdot \cos A_{\mathrm{s}}}=\frac{y-y_{i}}{\cos H_{\mathrm{s}} \cdot \sin A_{\mathrm{s}}}=\frac{z-z_{i}}{\sin H_{\mathrm{s}}} .
$$

Altitude $z_{\mathrm{e}}$ can be analytically derived by combining equations (1) and (5). For each leaf $i$, the value of $P_{0 \text { is }}$ is compared with a random number $T$ sampled between 0 and 1. If $T$ is lower than $P_{0 \mathrm{is}}$, the leaf is assumed to be sunlit and beam leaf irradiance $I_{\text {is }}$ is computed as a function of the relative geometry between the sun direction and the leaf orientation (e.g. [55]):

$I_{\text {is }}=\left(R b_{0} / \sin H_{\mathrm{s}}\right) \cdot\left|\cos \alpha_{i} \cdot \sin H_{\mathrm{s}}+\sin \alpha_{i} \cdot \cos H_{\mathrm{s}} \cdot \cos \left(A_{i}-A_{\mathrm{s}}\right)\right|$

where $R b_{0}$ is the incident direct radiation, $\alpha_{i}$ is leaf inclination and $A_{i}$ is leaf azimuth. If $T$ is greater than $P_{0 \text { is }}$, the leaf is assumed to be shaded and beam leaf irradiance $I_{\text {is }}$ is equal to zero. This simple stochastic process allows us to generate sunlit and shaded leaf populations whose partitioning depends on the spatial location within the tree.

For diffuse leaf irradiance, the sky is divided up into solid angle sectors $j$ corresponding to directions $\Omega_{j}$ of elevation $H_{j}$ and azimuth $A_{j}$. Assuming an isotropic distribution of the diffuse incident radiation [66], the flux $R d_{j}$ coming from each sector $j$ is

$R d_{j}=R d_{0} \cdot\left(\sin ^{2}\left[H_{j}+\mathrm{d} H\right]-\sin ^{2}\left[H_{j}-\mathrm{d} H\right]\right) \cdot(\mathrm{d} A / \pi)$

where $\mathrm{d} H=5^{\circ}$ and $\mathrm{d} A=15^{\circ}$ are respectively the halfsize of elevation and azimuth classes. $R d_{0}$ is the incident diffuse radiation above the tree.

For each direction $\Omega_{j}$, the attenuation of diffuse radiation $P_{0 i j}$ is computed from Goudriaan's form [25] of Beer's law

$$
P_{0 i j}=\exp \left[-D \cdot \frac{z_{\mathrm{e}}-z_{i}}{2 \cdot \sin H} \cdot \sqrt{1-\sigma}\right]
$$

where $\sigma$ is the scattering coefficient of leaves, i.e. the sum of leaf reflectance and transmittance $(\sigma \approx 0.2$ for photosynthetically active radiation). Including the term $\sqrt{1-\sigma}$ is a simple way to account for scattering in light attenuation [25]. Diffuse irradiance $I_{\mathrm{id}}$ of leaf $i$ is thus:

$$
I_{\mathrm{id}}=\sum_{\Omega_{j}}\left(R d_{j} / \sin H_{j}\right) \cdot P_{0 i j} \cdot\left|\cos \alpha_{i} \cdot \sin H_{j}+\sin \alpha_{i} \cdot \cos H_{j} \cdot \cos \left(A_{i}-A_{j}\right)\right| .
$$


The leaf irradiance submodel is used in SIMWAL in three cases. First, direct leaf irradiance is computed at each time step, i.e. when the sun direction changes. Second, when a new leaf appears, the ellipsoid parameters are updated, and the direct and diffuse irradiance of the new leaf is computed. Third, when the ellipsoid parameters have significantly changed (i.e. a $10 \%$ variation of any parameter), the direct and diffuse irradiances of all leaves are updated.

In the case of small trees without mutual shading, all leaves are assumed to be sunlit and receive diffuse radiation from every sky direction. Direct leaf irradiance $I_{\text {is }}$ is thus given by equation (6) while diffuse irradiance $I_{\text {id }}$ obeys equation (9) where $P_{0 i j}$ equals 1 . This leads to [65]:

$$
I_{\mathrm{id}}=R d_{0} \cdot \cos ^{2}\left(\alpha_{i} / 2\right) \text {. }
$$

\section{Carbon gains and losses}

Leaf photosynthesis is simulated with an hourly time step according to Farquhar et al. [21]. The Farquhar model was used because it provides a physiologically sound approach to account for the effect of $\mathrm{CO}_{2}$ and temperature on leaf photosynthetic rate. The model version proposed by Harley et al. [26] was used without including the potential limitation arising from triose phosphate utilisation. Net $\mathrm{CO}_{2}$ photosynthetic rate $\left(P_{n}, \mu \mathrm{mol} \mathrm{CO}_{2}\right.$ $\left.\mathrm{m}^{-2} \mathrm{~s}^{-1}\right)$ is expressed as

$$
P_{n}=\left[1-\left(0.5 \mathrm{O} /\left(\tau C_{i}\right)\right)\right] \min \left(W_{\mathrm{c}}, W_{j}\right)+R_{\mathrm{d}} .
$$

where $W_{\mathrm{c}}\left(\mu \mathrm{mol} \mathrm{CO}_{2} \mathrm{~m}^{-2} \mathrm{~s}^{-1}\right)$ is the carboxylation rate limited by the amount, activation state and/or kinetic properties of Rubisco, $W_{j}\left(\mu \mathrm{mol} \mathrm{CO} \mathrm{CO}^{-2} \mathrm{~s}^{-1}\right)$ is the carboxylation rate limited by the rate of $\mathrm{RuP}_{2}$ regeneration, $\tau$ is the specificity factor for Rubisco, $R_{\mathrm{d}}\left(\mu \mathrm{mol} \mathrm{CO} \mathrm{Cm}^{-2}\right.$ $\mathrm{s}^{-1}$ ) is the rate of $\mathrm{CO}_{2}$ evolution in light that results from processes other than photorespiration, and $\mathrm{O}$ and $C_{i}(\mathrm{~Pa})$ are respectively the partial pressures of $\mathrm{O}_{2}$ and $\mathrm{CO}_{2}$ in the intercellular air spaces. Rubisco activity is likely to restrict assimilation rates under conditions of high irradiance and low $C_{i} \cdot \mathrm{RuP}_{2}$ regeneration is likely to be limiting at low irradiance and when $C_{i}$ is high. At a given leaf temperature, the key model parameters (maximum carboxylation rate, maximum electron transport rate, and respiration rate) are linearly related to leaf nitrogen content on an area basis $N_{a}$ [41]. $N_{a}$ is correlated to the actual time-integrated leaf irradiance $\left\langle\mathrm{PAR}_{i}\right\rangle$ as [40]:

$$
N_{a}=a+b N_{0}<\mathrm{PAR}_{i}>/<\mathrm{PAR}_{i 0}>
$$

where $\left\langle\mathrm{PAR}_{i 0}\right\rangle$ and $N_{0}$ are respectively the mean irradiance and nitrogen content of fully sunlit leaves. The temperature dependence of the key model parameters is given in Harley et al. [26] (leaf temperature is assumed to be equal to air temperature). Two approaches can be used to compute $C_{i}$ in the current version of the model. In the first approach, valid only for high air humidity and no water stress, the ratio of the partial pressure of $\mathrm{CO}_{2}$ in the intercellular air spaces to the partial pressure of $\mathrm{CO}_{2}$ in the air $C_{i} / C_{a}$ is computed by an empirical function of leaf irradiance $\mathrm{PAR}_{i}$ (Le Roux, unpublished, established for leaves of young and old walnut trees):

$$
C_{i} / C_{a}=\frac{\left(\mathrm{PAR}_{i}+51.1\right)}{\left(1.538 \mathrm{PAR}_{i}+40.88\right)}
$$

In the second approach, stomatal conductance is computed according to Jarvis [29]. This model assumes that the stomatal conductance $g_{\mathrm{s}}$ is affected by non-synergistic interactions between plant and environmental variables. Thus, $g_{\mathrm{s}}\left(\mathrm{mmol} \mathrm{H}_{2} \mathrm{O} \mathrm{m}^{-2} \mathrm{~s}^{-1}\right)$ is computed as

$$
g_{\mathrm{s}}=g_{\mathrm{s} \max } f(\mathrm{PAR}) f(\mathrm{VPD}) f\left(C_{a}\right)
$$

where VPD is the air water vapour pressure deficit at the leaf surface $(\mathrm{Pa}), C_{a}$ is the air $\mathrm{CO}_{2}$ concentration $(\mathrm{Pa})$, and $g_{\text {s max }}$ is the maximum stomatal conductance. $g_{\text {s max }}$ is empirically computed according to the leaf radiation regime to account for the relationship between leaf photosynthetic capacity and $g_{\text {s } \max }$ [41]. When using the second approach, an analytical solution is used to couple the photosynthesis and stomatal conductance submodels [67].

Water restriction is not considered in the present version of the model. Leaf ageing is accounted for by an empirical relationship, whereby photosynthetic rates increase from budbreak until late July and decrease in September and October [31]. Leaf fall arbitrarily occurs on 1 November. A detailed version of the photosynthesis submodel and a complete list of the parameters determined for walnut are given in [41].

Carbon losses are split into growth respiration $R_{\mathrm{g}}$ (associated with the synthesis of new biomass) and maintenance respiration $R_{\mathrm{m}}$ (associated with the maintenance and turn-over of existing biomass). As each type of organ has a different chemical composition, respiration is computed at the organ scale. $R_{\mathrm{m}}$ is assumed to be proportional to the amount of structural carbon $w_{\mathrm{st}}$ (gDM) in each organ [47]:

$$
R_{\mathrm{m}}=m w_{\mathrm{st}}
$$

where $m$ is the maintenance coefficient $\left(\mathrm{gCO}_{2} \mathrm{gDM}^{-1}\right.$ day $^{-1}$ ). Individual $m$ values are not determined for each organ; when unknown for a given type of organ, $m$ is set as proportional to the maximum carbohydrates content of this organ, assuming this content reflects its proportion of live DM. This is supported by the following assumptions: (i) for a given organ, the ratio of live DM to total DM is proportional to its ability to store reserves (i.e., the live DM is assumed to be made essentially of 
parenchyma cells of equivalent capacity), and (ii) the maximum carbohydrates content is reflected in this capacity of storage. The parameter $m$ is modulated by temperature using a $Q_{10}$ value of 2 [30].

$R_{\mathrm{g}}$ is proportional to the structural dry matter increase $\Delta w_{\mathrm{st}}\left(\mathrm{gDM} \mathrm{day}^{-1}\right)$ :

$$
R_{\mathrm{g}}=\frac{1-Y_{\mathrm{g}}}{Y_{\mathrm{g}}} \Delta w_{\mathrm{st}}
$$

where growth efficiency $Y_{\mathrm{g}}$ is defined as the proportion of the total $C$ allocated to growth that is actually incorporated into the new DM [62]. Its value is generally close to 0.7 to 0.8 [56]. We chose a value of 0.75 for all the organs except fine roots which have a high turn-over. Modelling root mortality could be done by removing constructed tissues. However, to simplify the way of modelling this process in this first version of the model, we lowered the value of $Y_{\mathrm{g}}$ to 0.5 for the fine roots (in Eq. (16) $\Delta w_{\text {st }}$ is only the increment in structural dry matter without considering mortality losses).

\section{Carbon partitioning}

The carbon allocation submodel in SIMWAL is basically a proportional model [34]. However, two major extensions have been included to account for significant features of carbon allocation in real trees:

1. Non-proportional changes in relative sink allocation, as observed for significant source-sink ratio changes, are allowed through splitting the local "sink strength", which is determined by a single parameter in basic proportional models, into two different components. These are a $\mathrm{C}$ demand, analogous to an affinity, which drives allocation at low $\mathrm{C}$ availability, and a maximum import rate, which controls $\mathrm{C}$ allocation at high $\mathrm{C}$ availability. A similar extension of proportional models can be found in Escobar-Guttierrez et al. [20].

2. The decrease in $\mathrm{C}$ fluxes between source and sink with increasing pathway length, a major characteristic of carbon allocation within trees [34], is taken into account by computing the fluxes from a given individual source allocated to the different individual sinks as proportional not only to their demand, but also to a coefficient that is a decreasing function of the source-sink distance. Thus, the amount of carbohydrates flowing from an individual source $\# i$ to an individual sink $\# j$, as allocated by the model regardless of any maximum import rate limitation, is:

$$
F_{i j}=\frac{A_{j} \cdot f\left(d_{i j}\right)}{\sum_{k}\left[A_{k} \cdot f\left(d_{i k}\right)\right]} \cdot A C_{\mathrm{N} i}
$$

where $A C_{\mathrm{N} i}$ is the net amount of carbohydrates exported by source $\# i, A_{j}$ the affinity or demand of sink $\# j$, and $f\left(d_{i j}\right)$ a decreasing function of the distance between the two partners. $d_{i j}$ is the metric length between $i$ and $j$ but following the topological path (i.e. following the different junctions between the GUs). In the present version of SIMWAL, $f\left(d_{i j}\right)$ was chosen after testing different forms [37] as:

$$
f\left(d_{i j}\right)=\left(d_{i j}+a\right)^{-\lambda}
$$

where $a(\mathrm{~cm})$ and $\lambda$ (dimensionless) are two parameters determined empirically by moving forward by trial and error.

Summing for all possible sources yields the total amount of carbohydrates allocated to sink \#j. However, if this exceeds the maximum that can be imported by sink $\# j$, the actual amount imported will be the maximum import rate, $B_{j}$ :

$$
F_{j}=\min \left(\sum_{i} F_{i j}, B_{j}\right)
$$

and the carbohydrates allocated in excess are retained to be allocated at the next time step, together with the carbon that will be released by the different sources at that next time step. This can be regarded as the short-term storage that occurs in leaves or conducting tissues (see review by Lacointe et al. [36] and refs. therein).

This approach, although very simple in its formulation, allows very flexible allocation patterns based on source-sink relationships, including spatial aspects, which take into account some architectural information. A similar approach is used for continuous diffuse sinks such as radial growth (see [37] for details).

\section{Sources and sinks}

In SIMWAL there are basically two $\mathrm{C}$ sources: photosynthesis and reserve remobilisation. Reserve remobilisation takes place in winter and spring when photosynthesis is nil or insufficient to supply the different organs. In winter, each organ is assumed to live on its own reserves for maintenance respiration. In spring, organ reserves are used for respiration and growth until photosynthesis reaches or exceeds C demand. Each organ uses firstly its own local reserves, then reserves from the closest storage organ, then if necessary the second closest organ, etc. For biological reasons, the reserve content of a given organ cannot drop below a given threshold. Therefore when this threshold is reached, reserves from another organ are used to supply a given sink. If all the organs are below the threshold, reserves are no longer mobilised. 
The demand of each organ (sink) is split into three components: maintenance respiration $R_{\mathrm{m}}$ (Eq. 15), growth (structure extension and associated respiration $R_{\mathrm{g}}$, Eq. 16), and reserve reconstitution (after spring mobilisation) or storage (for new organs). In SIMWAL growth and reserve storage occur at the same time, at the organ level, which is consistent with biological observations [31]. The following two sections describe the growth and reserve storage processes.

\section{Growth processes}

We distinguish three growth processes; (i) bud growth until budbreak, (ii) elongation of new shoots, roots and leaves, and (iii) radial growth of pre-existent and new organs (shoot or root). Carbon allocation and growth processes are developed in two distinct submodels in SIMWAL. However, they are intimately linked to each other by the following processes; (i) growth is limited by the carbon availability at a given time $t$, and (ii) growth demand at $t$ is adjusted according to growth at $t-1$ and consequently according to $\mathrm{C}$ availability at $t-1$ (i.e. if $\mathrm{C}$ availability allows growth to be high at $t-1$, the demand at $t$ may be greater than at $t-1$ and vice versa). The growth of a given organ is therefore not entirely defined and depends on $\mathrm{C}$ availability. This feature gives SIMW$\mathrm{AL}$ a certain plasticity particularly in relation to external factors (climate, pruning).

\section{Bud growth}

Bud growth is driven by air temperature. We take 1 January as the date of bud dormancy release whatever the annual climate. This approximation introduces very little error under temperate climates, where temperatures inducing fast bud growth do not occur before February or March [3]. This should not be the case using the model with other types of climate. Branching rules for walnut and variability in crown development are taken into account by computing the probability of budburst $P_{\mathrm{b}}$ for each bud $j$ according to the bud position in the tree and GU characteristics:

$$
\begin{aligned}
P_{\mathrm{b}}(j)= & f_{1}(\text { axis order }) \times f_{2}(\mathrm{GU} \text { volume }) \\
& \times f_{3}(\text { bud position }) \times f_{4}(\text { GU reserve })
\end{aligned}
$$

where $f_{i}$ are empirical multiplier functions between 0 and 1 (for details see [37]). On 1 January, the drawing of a random number $T$ determines if budburst occurs $\left(T<P_{\mathrm{b}}(j)\right)$ or not $\left(T>P_{\mathrm{b}}(j)\right)$. There is also a second random draw to test if latent buds (buds two or more year old) will die or not, the probability of dying increasing with bud age. Buds predetermined to burst in spring grow according to an exponential law [51]:

$$
w_{\mathrm{b}}(j)=w_{\mathrm{b} 0} \cdot \exp [\Phi(k)]
$$

where $w_{\mathrm{b}}(j)$ is the weight of the bud $j, w_{\mathrm{b} 0}$ is the initial weight of the bud on 1 January and for each type $k$ of bud (apical or axillary) $\Phi$ increases linearly with the amount of accumulated temperatures above the threshold of $4.5{ }^{\circ} \mathrm{C}$ [53]. The increase in $w_{\mathrm{b}}$ at a given time $t$ is then converted into a carbon demand $(D(t))$. According to phenological observations, apical buds grow faster than axillary ones (for details see [37]).

\section{Shoot elongation}

From biological observations, the growth of a new shoot takes place in two phases: cellular multiplication and elongation. The number of cells obtained at the end of the multiplication stage determines the maximal potential elongation of the organ (i.e., after the multiplication phase no new cellular division occurs and cells have finite elongation possibilities). Provided assimilate availability is sufficient, the multiplication phase is described by an exponential law (cf. Eq. (22)). Elongation is described by a logistic law (cf. Eq. (25)). It is defined by continuation of the exponential law for the small values while the upper asymptote is proportional to the point reached at the end of the exponential phase for a non limiting carbon supply [37]. In the case of limiting assimilates, the point reached at the end of the exponential curve will be lower, and hence so will be the maximum of the logistic curve. The slope of the logistic curve $(\beta$, see Eq. (25)) gives at each time step the maximum elongation rate of the organ provided assimilates are not limiting.

Mathematically, for a given organ in its exponential phase, carbon demand $D(t)$ at time $t$ is proportional to its weight $w$ at $t-1$ :

$$
D(t)=c(t) \times w(t-1) \text { with } c(t)=c_{0} \times g(t-1)
$$

where $c(t)$ is a proportionality parameter, $c_{0}$ is the value of $c$ if available assimilates do not exceed demand, and $g(t-1)$ is an increasing function of the amount of assimilates in excess $(\varepsilon(t-1))$ with respect to the organ demand at $t-1 . g(t-1)$ varies between 1 and $g_{\max }$ as a function of $\varepsilon(t-1)$ :

$$
\begin{gathered}
g(t-1)=1 \text { for } \varepsilon(t-1) \leq 0 \\
1<g(t-1)<g_{\max } \text { for } 0<\varepsilon(t-1) \leq \varepsilon_{\text {threshold }} \\
g(t-1)=g_{\max } \text { for } \varepsilon(t-1)>\varepsilon_{\text {threshold }}
\end{gathered}
$$

where $g_{\max }$ is the maximum value of $g(t-1)$ and $\varepsilon_{\text {threshold }}$ corresponds to a certain amount of assimilates in excess. $\varepsilon_{\text {threshold }}$ is proportional to the carbon demand at $t-1$ $(D(t-1)$ :

$$
\varepsilon_{\text {threshold }}=\gamma(k) \cdot D(t-1)
$$


where $\gamma(k)$ is a factor of proportionality $(\gamma(k)>0)$ depending on the type $k$ of organ.

For a given organ in the logistic phase, its potential dimension $E(t)$ at time $t$ is given by:

$$
E(t)=\frac{E_{\mathrm{m}}}{1+\exp \left[-\beta\left(t-t_{\text {ip }}\right)\right]}
$$

where $E_{\mathrm{m}}$ is the asymptote of the curve, $t_{\mathrm{ip}}$ is $x$ coordinate of the inflection point (which is also the point with a $y$ coordinate $E_{\mathrm{m}} / 2$ ) and $\beta$ controls the slope.

\section{Radial growth}

For organs aged one year or more, we assume their radial growth begins once they have reconstituted their reserve after spring mobilisation. For new shoots, radial growth begins once their first internode has ended its elongation. Reserve storage is assumed to be concomitant with radial growth. Therefore a given organ at a given time $t$ has a demand $D(t)$ for assimilates for both the new structure and reserve storage. This demand $D(t)$ is directly linked to the assimilates available at $t-1$ :

$$
D(t)=\Delta C(t-1)
$$

where $\Delta C(t-1)$ is the amount of carbon that has actually been incorporated in the organ at $t-1$ according to assimilate availability. This formulation relies on the observation that the activity of the enzymatic system, which determines the sink strength, responds fairly directly to the local concentration in assimilates and particularly sucrose [18]. If there is an excess of assimilates, the incorporation of carbon in a given organ can exceed the demand $D(t)$. However, $D(t)$ is limited by a maximal value $\left(D_{\max }\right)$ corresponding to the assumed physical limits of cell division rate. Therefore $D(t)=\min [\Delta C(t-1)$, $\left.D_{\max }\right]$.

\section{Fine root growth}

The growth of fine roots is modelled separately to take into account their ability to grow throughout the year according to soil temperature (water and mineral nutrients being non-limiting $[12,54])$. Fine root growth rate $V\left(\mathrm{~cm} \mathrm{day}^{-1} \mathrm{gDM}^{-1}\right)$ is computed as:

$$
V=V_{\text {opt }}\left\{1-\left[\left(T-T_{\text {opt }}\right)^{2} /\left(T_{\mathrm{t}}-T_{\text {opt }}\right)^{2}\right]\right\}
$$

where $V_{\max }$ is the maximal growth rate, and $T, T_{\mathrm{t}}$ and $T_{\mathrm{opt}}$ are respectively the soil temperature at $20 \mathrm{~cm}$ depth $\left({ }^{\circ} \mathrm{C}\right)$, the threshold temperature at which growth can occur and the optimum temperature where $V=V_{\max }$. A carbon demand $D(t)$ corresponding to the structure increment according to $V$ is then calculated at each time step.

\section{Tree pruning}

A pruning operation has two major effects: budbreak of latent buds and modification of the growth of organs that were already growing $[2,4]$. A tree shows a complex of inhibitive correlations [10], i.e. the growth of a given organ is under the control of other organs that can prevent it growing (for instance in apical dominance, the growing apical bud prevents the axillary buds growing). Therefore, by suppressing some organs, pruning can break (though not always, see below) this complex of inhibitive correlations, and some latent buds that were previously inhibited can grow and give birth to new shoots. For a given bud, its budbreak probability after pruning $\left(P_{\mathrm{p}}\right)$ depends on $[1,42,43]$ :

1. Its position within the tree below the point of pruning. A bud close to the pruning point has a better chance of breaking than a bud farther away;

2. The amount of foliage or organs removed by pruning. The growth of a bud is inhibited by many other organs (see above). This means that $P_{\mathrm{p}}$ increases with the number of inhibiting organs removed;

3. The number of buds that were already growing at the time of pruning (NBG). The larger NBG will be near the pruning point, the lower $P_{\mathrm{p}}$;

4. The date of pruning. $P_{\mathrm{p}}$ is close to 1 in spring and then progressively decreases during the growing season;

5. The characteristics of the GUs (age, branching order, number of growing points).

Budbreak after pruning is assumed to occur only in a zone $Z_{\mathrm{p}}$ of the tree close to the pruning point but whose dimension (length, in $\mathrm{m}$ ) depends on the amount of wood removed. As a first approximation, $Z_{\mathrm{p}}$ is equal to the length $L(\mathrm{~m})$ of wood removed by pruning. $Z_{\mathrm{p}}$ starts at the pruning point and extends towards the root system. $P_{\mathrm{p}}$ for a given bud in $Z_{\mathrm{p}}$ is then computed according to:

$$
P_{\mathrm{p}}=f_{1}(L) \times f_{2}(\mathrm{NBG}) \times f_{3} \text { (Pruning Date) }
$$$$
\times f_{4}(\text { GU Order }) \times f_{5}(\text { GU Age })
$$

where $f_{i}$ are different empirical multiplier functions between 0 and 1 [37].

The subsequent growth of the shoots born from budbreaks after pruning is driven in the same way as growth described in the previous section, except that their final characteristics (maximal dimensions, $E_{\mathrm{mp}}$ ) are calculated from those they would have had without pruning $\left(E_{\mathrm{m}}\right)$, added to the probability of budburst:

$$
E_{\mathrm{mp}}=E_{\mathrm{m}}\left(1+P_{\mathrm{p}} / 2\right) \text {. }
$$

This expression accounts for the observation that a shoot born after pruning often has greater growth potential than the other shoots. This potential depends on the same 
characteristics as $P_{\mathrm{p}}$ (for instance a shoot born in August will have weak growth potential compared with one born in June). Introducing $P_{\mathrm{p}}$ in equation (29) accounts for this effect without overcomplicating the calculations (for instance $P_{\mathrm{p}}$ will be low in August leading to $E_{\mathrm{mp}} \approx E_{\mathrm{m}}$ ). As for a shoot born in spring, shoot growth after pruning depends on assimilate availability. Therefore in the case of heavy pruning (i.e., heavily reducing leaf area), the amounts of available assimilates will decrease, leading to reduced growth. In this version of SIMWAL, the organ reserves are not expected to take part in the carbon supply following pruning.

\subsection{Model inputs and data analysis}

\section{Initial trees, input parameters and climate}

As far as possible, initial trees and input parameters in simulations were drawn from our experiments on living trees. Otherwise, parameter values were taken directly from the literature. Different initial trees were used to test the consistency of the different submodels, according to the available experimental data [31, 37, 41]: 2, 3 and 5 year-old trees were used for photosynthesis, architectural and carbon allocation, and pruning simulations, respectively. Actual climate data recorded at ClermontFerrand, France, and corresponding to the years of the different experiments were used (i.e., 1992, 1995 and 1997). Meteorological variables were minimal and maximal daily air temperatures, mean daily soil temperature at $20 \mathrm{~cm}$ depth, daily global radiation, daily hours of sunshine and daily air VPD. Hourly values of air temperature and radiation were computed from daily values [37]. The air $\mathrm{CO}_{2}$ content was set at $350 \mathrm{ppm}$ for all the simulations.

We simulated three pruning intensities as performed in an experiment in June 1997; 0, 20 or $40 \%$ of the ramifications along the trunk of young walnut were cut. This is common practice in timber walnut plantations to obtain knot-free boles [4].

\section{Result analysis}

We compared simulation results with field observations as far as possible. However, data were not analysed statistically for several reasons. One was that the model uses probability calculations in several cases. Therefore, a statistical analysis would require running the model many times to obtain the distribution of the output values. Prohibitively long simulation duration made this impossible. Simulation time lengths in this first version of SIMWAL also prevented simulation of trees older than five years. Hence we had to compare simulated 5year-old pruned trees with experimental data obtained on 9-year-old trees. In this case, only a qualitative comparison was possible. However, as the structures of simulated 5-year-old trees and observed 9-year-old ones were very close, the comparison of qualitative variations of simulated and observed tree structure after pruning was possible (we have not attempted a strict quantitative analysis of data). In this part of the work, our purpose was to test the consistency of each submodel of SIMWAL rather than to validate it in a strict sense.

\section{RESULTS}

\subsection{Tree architecture}

Starting from the same initial tree without any ramification, we compared the observed and simulated architecture dynamics (number of new GUs and their length) of this tree in 1992 (figure 2). At the end of 1992, the observed tree had nine ramifications of which four were very small while the simulated tree had only six. However, the difference between the two trees was only obtained for the small ramifications which had a limited number of internodes resulting from a process of abortion, relatively common in walnut. This process was not taken into account in SIMWAL.

The mean GU length for the simulated tree was greater than for the observed tree. Generally simulated GUs had more and longer internodes. However, simulations were run with no water or nutrient limitation, which was not the case in the field. This can explain that the simulated tree had longer ramifications.

\subsection{Tree photosynthesis}

When using the simple $C_{i} / C_{a}=f\left(\mathrm{PAR}_{i}\right)$ approach, the model greatly overestimated the observed photosynthetic rate at branch scale (figure 3). The effect of high air water vapour pressure deficits (4 $\mathrm{kPa}$ at midday), which was not taken into account in this approach, explains the discrepancy. In contrast, simulated photosynthetic rates were close to observed ones when using Jarvis' model of stomatal conductance. The model predicted a weak midday depression, which was not observed. However, together with previous validation exercises [41], this comparison indicates that the simulated local carbon input rates (i.e. resulting from both the radiation interception and photosynthesis submodels) were consistent with observed rates, especially at daily scale. 


\subsection{Carbon partitioning at tree scale}

Figure 4 shows the $\mathrm{C}$ partitioning between the different organs of a 5-year-old tree in 1995. Daily tree C assimilation followed the seasonal course of radiation

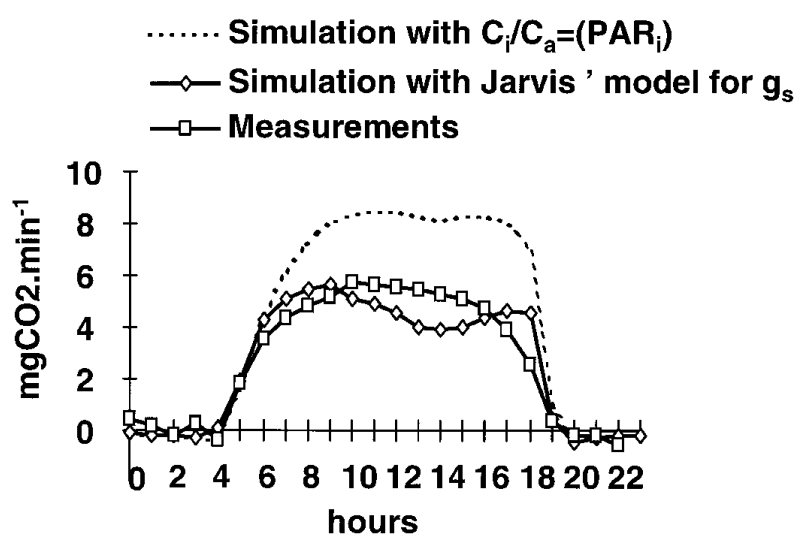

Figure 3. Comparison of the observed and simulated values of the net carbon assimilation on 24 July 1995 of a whole GU of a small tree with two GUs (simulation was performed using either Jarvis' model of stomatal conductance or the simple $C_{i} / C_{a}=f\left(\mathrm{PAR}_{i}\right)$ approach $)$. fairly closely, radiation being the main factor driving photosynthesis and consequently tree development in the model. In spring $\mathrm{C}$ was preferentially incorporated into leaves and new GUs. During this period C came essentially from reserve mobilisation, photosynthesis being very limited (data not shown). There was then reconstitution of the reserves, in trunk and roots. Then $\mathrm{C}$ was essentially allocated to root and shoot radial growths. At the end of the season, $\mathrm{C}$ is essentially used for respiration. This sharing out shows no discrepancy with biological observations $[31,35]$.

At tree scale, we compared simulations and measurements for the proportion of $\mathrm{C}$ allocated to the different $\mathrm{C}$ functions over one vegetation cycle (table I): shoot and

Table I. Annual global C balance (in \% of net assimilation) for a 5-year-old walnut tree in 1995.

\begin{tabular}{lcc}
\hline & Measurement & Simulation \\
\hline $\begin{array}{l}\text { Net assimilation } \\
\text { Night respiration } \\
\text { of the above-ground part }\end{array}$ & 100 & 100 \\
Root respiration & 25 & 16 \\
Biomass increase & 22 & 22 \\
\end{tabular}

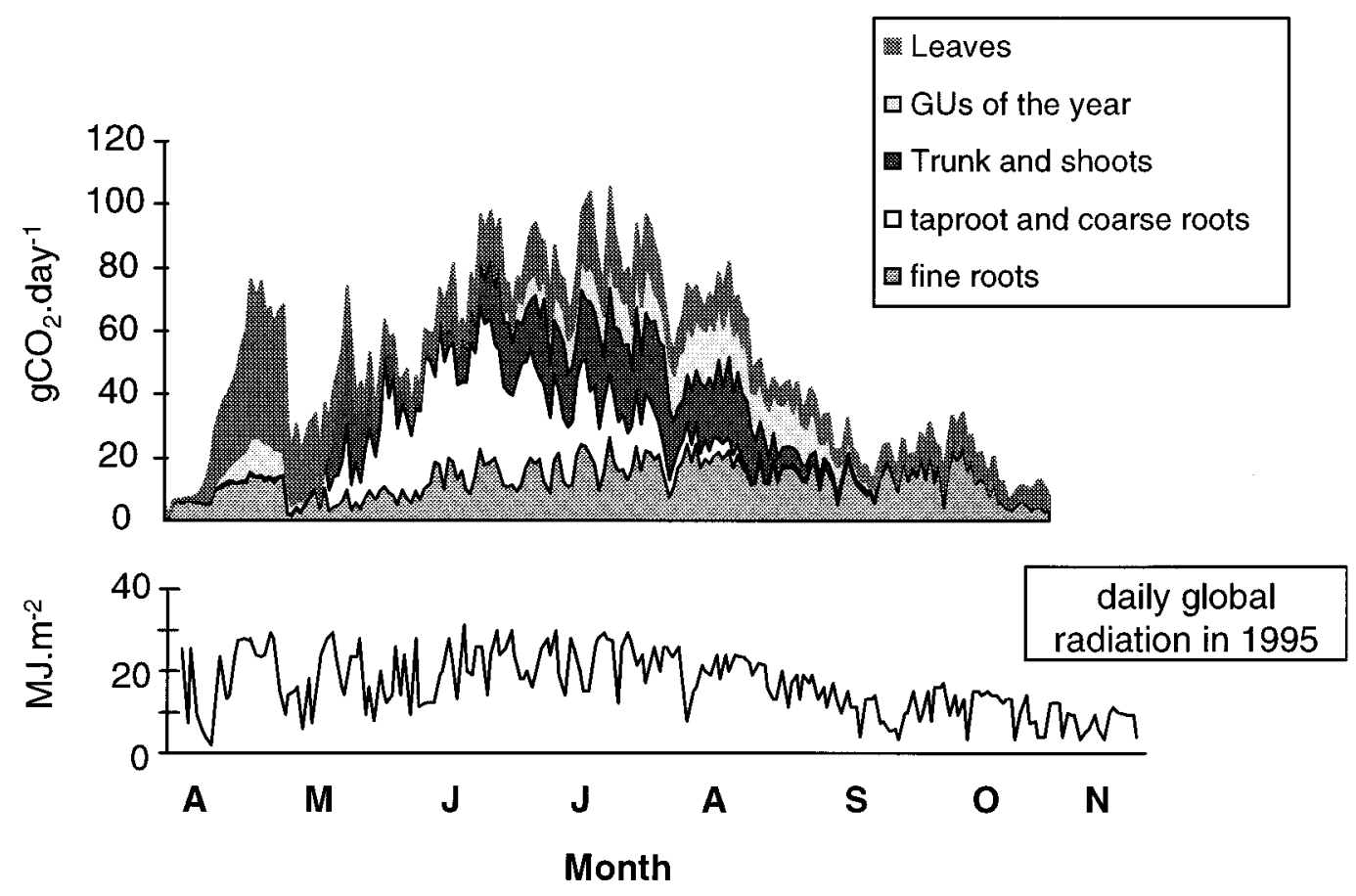

Figure 4. Simulation of carbon (resulting from reserves remobilisation or photosynthesis) partitioning among the different organs (C allocated to growth or respiration undistinctly) in 1995 for a 5-year-old tree. 
Table II. Simulated and measured tree reactions after pruning performed in June 1997. Three pruning intensities were tested: 0,20 and $40 \%$ of the axes along the trunk were cut.

\begin{tabular}{lcccccc}
\hline & \multicolumn{3}{c}{ Measurement } & \multicolumn{3}{c}{ Simulation } \\
\hline $\begin{array}{l}\text { Treatment } \\
\begin{array}{l}\text { Number of new } \\
\text { shoots appearing } \\
\text { after pruning }\end{array}\end{array}$ & $0 \%$ & $20 \%$ & $40 \%$ & $0 \%$ & $20 \%$ & $40 \%$ \\
$\begin{array}{l}\text { Shoot diameter } \\
\text { increase at the end } \\
\text { of the year (\% of } \\
\text { the initial diameter) }\end{array}$ & $17.6^{\mathrm{a}, *}$ & $20.1^{\mathrm{b}}$ & $16.3^{\mathrm{a}}$ & 29.4 & 49.4 & 30.5 \\
\hline
\end{tabular}

* For measurements only, the same letter indicates that values are not significantly different at the $5 \%$ level.

root respiration rates, and biomass increase (i.e., sum of growth and reserve storage processes). Shoot night respiration was a slightly underestimated by the model. In contrast, biomass increase was a little overestimated. Root respiration seemed well simulated. Considering that data resulted from integration over a whole growth period, the deviations between simulated and observed values of $\mathrm{C}$ partitioning in functions and organs were rather low.

\subsection{Tree pruning}

We observed an average of 2.5 new shoots per tree after the $40 \%$ pruning treatment against no new shoot for both the 0 and 20\% treatments in 1997 (results from 12 trees per treatment, table II). Simulations showed results very close to observations ( 0 new shoots for the 0 and $20 \%$ pruning treatment and 2 for the $40 \%$ treatment).

The diameter increment of shoots was significantly greater for the $20 \%$ treatment than for the control, which is a classical observation (table II). The $40 \%$ treatment removed too much leaf area to allow the same increase and consequently shoot diameter growth was not statistically different from control. Qualitatively, simulations gave the same results (the 0 and $40 \%$ treatments were close, while the $20 \%$ treatment was much higher), but all the values were overestimated compared with observations. Together with a potential problem of parametrisation, this discrepancy may also result from the fact that water and nutrients were not limiting in the model, which was not the case in the field.

\section{DISCUSSION}

The results presented here show that the model is globally consistent with observations. Tree architectural development, photosynthesis, $\mathrm{C}$ allocation in organs and functions show no erratic pattern, although there are some quantitative discrepancies between simulations and observations. Validation in the strict sense would require many more simulations to test the sensitivity of the main parameters, to establish the output variable distributions, etc. This was out of the scope of this work. We have ascertained that the model simulates walnut development consistently, allowing further work.

SIMWAL presents several novel features. The first is the reciprocal relationships linking growth processes to $\mathrm{C}$ partitioning. The intimate link between these processes allows close simulation of climate and pruning effects on (i) tree structure development, and (ii) the adjustment of processes to the new external conditions. When climatic conditions change, tree $\mathrm{C}$ supply changes accordingly, and organ growth is modified in proportion. At the next time step, to fit this change in local $\mathrm{C}$ supply, the organ growth demand will be adjusted, and so on. Assimilate partitioning is the second novel feature of SIMWAL. The formalisation used (i) allows clear identification of sink strengths and supply sources at the organ scale, and (ii) takes into account the distance between the different organs (see [34] for details). We explicitly split sink demand in respiration, growth and reserve storage, while in numerous models respiration is often subtracted before $\mathrm{C}$ allocation among organs, and reserve storage is often uncoupled with growth processes [34]. In many models only excess carbon is allocated to the reserves, while biological observations show this is not as simple as that [9]. By construction, SIMWAL clearly simulates the reserve dynamics and particularly reserve remobilisation and organ reserve reconstitution. The third novel feature is the way of representing the growth processes in two distinct stages, in agreement with biological observations: i) the exponential phase (cellular multiplication) which determines the potential final size of an organ and ii) the elongation phase. Both are conditioned by carbohydrates availability. Finally, tree reaction to pruning is modelled taking into account the inhibitive correlations among organs at tree scale. Pruning breaks this complex of inhibitive correlations and leads to the development of latent buds. In SIMWAL, inhibitive correlations are modelled empirically by computing the distance over which pruning suppresses correlations (i.e., in determining the wood length in which buds can react to pruning) in relation to intensity, date, etc. of pruning. A better way of modelling inhibitive correlations would be directly to model the processes leading to the inhibition of one organ by another. However, these processes still remain largely unknown [1]. We artificially increased the growth demand of the sylleptic shoots born following pruning. Another way of modelling this process would be to increase $\mathrm{C}$ supply instead of $\mathrm{C}$ demand, and in 
particular to mobilise organ reserves following pruning. This has not yet been tested in SIMWAL. Another way of modelling the effect of pruning has been used by Génard et al. [24]. In this case, pruning modifies the shoot-root ratio and tree growth is then modified to restore this equilibrium between the above- and belowground parts. However, the model was only tested on a 1 -year-old peach tree with very simple root and shoot architectures and did not consider budbreak possibilities of latent buds.

SIMWAL has of course some limitations. Some are of biological or physiological nature, others are linked to programming difficulties or data processing limitations. Concerning biological processes, bud dormancy is broken on 1 January whatever the climate, which is not very realistic. We could improve this by modelling bud dormancy dynamics according to temperature (see [3]). This improvement would also enable us to model winter pruning effects, which is not possible at present. A greater limitation of SIMWAL is taking water and nutrients to be optimum. This assumption naturally leads to an overestimation of tree growth as shown in the results. In addition to these limitations, choosing the form and adjusting the distance function $f\left(d_{i j}\right)$ in the $\mathrm{C}$ partitioning submodel is a key problem in SIMWAL. Bad choices lead to an unbalanced growth between above- and below-ground parts (no a priori assumption is made about the root-shoot ratio). Apart from problems of parametrisation, the difficulty of reaching a correct rootshoot ratio is perhaps also linked to the fact that there is no water or nutrient control in the model. Water and nutrients (particularly nitrogen) could implicitly restore the root-shoot ratio, by limiting either root or shoot development [63]. Accounting for water fluxes and nutrient balance would thus be required, but this would imply substantial modifications of SIMWAL. The last major limitation of SIMWAL is the extreme simplification of the root system in comparison with the complex above-ground part. Consequently, it seems that we cannot take this model further without modelling a root system with a minimum of architectural and physiological processes. Attempts are currently being made to merge allocation and architectural root models to improve their ability to simulate root development and root-shoot relationships $[46,61]$. We also need a realistic 3D development of the root system to model nutrient and water absorption correctly.

However, such modifications will further increase the complexity of SIMWAL, which is already limited by calculation time. At present we cannot simulate walnut trees bigger than 5- or 6-year-old. We need to improve the programming, and also to test some simplifications of the model. In particular, there may be no point in sim- ulating a 20-year-old tree at leaf scale. Bulking organs of similar nature and spatially close to each other (e.g. using leaf clusters instead of individual leaves) is one possible solution we will be investigating.

Acknowledgements: The authors thanks A. Marquier and F. Landré for their technical contributions in the field. The study was supported by a grant from the French Ministry of Agriculture, Directorate for Forests and Rural Environment (DERF).

\section{REFERENCES}

[1] Balandier P., Étude dynamique de la croissance et du développement des bourgeons de quelques cultivars de pêcher cultivés à diverses altitudes sous le climat tropical de l'île de la Réunion, Ph.D. Thesis, Université de Clermont-Ferrand II, France, 1992, 90 pp. + ann.

[2] Balandier P., A method to evaluate needs and efficiency of formative pruning of fast-growing broad-leaved trees and results of an annual pruning, Can. J. For. Res. 27, 6 (1997) 809-816.

[3] Balandier P., Bonhomme M., Rageau R., Capitan F., Parisot E., Leaf bud endodormancy release in peach trees: evaluation of temperature models in temperate and tropical climates, Agric. For. Meteor. 67 (1993) 95-113.

[4] Balandier P., Le Dizès S., Jacquet P., Cruiziat P., Formation de la bille de pied en culture d'arbres à bois précieux, DERF convention report, Cemagref, Clermont-Ferrand, France (1996), 83 pp.

[5] Barczi J.F., Reffye (De) P., Caraglio Y., Essai sur l'identification et la mise en œuvre des paramètres nécessaires à la simulation d'une architecture végétale, In Modélisation et simulation de l'architecture des végétaux, Bouchon J., De Reffye P., Barthélémy D. (Eds.), INRA Ed., Versailles, France, Coll. Science Update, 1997, pp. 205-254.

[6] Bartelink H.H., A model of dry matter partitioning in trees, Tree Physiol. 18 (1998) 91-101.

[7] Bouchon J., Houllier F., Une brève histoire de la modélisation de la production des peuplements forestiers : place des méthodes architecturales, In Architecture des arbres fruitiers et forestiers, Montpellier, France, 1993/11/23-25, INRA Ed., Paris, Les colloques 74 (1995) 17-25.

[8] Boussoualine H., Amélioration d'INCA, outil de simulation de la croissance de l'arbre, mémoire ISIMA et DEA informatique, Clermont-Ferrand, France, 1997, 70 pp. + ann.

[9] Canell M.G.R., Dewar R.C., Carbon allocation in trees: a review of concepts for modelling. In: Begon M. and Fitter A.H. (Eds.), Advances in ecological research, Academic Press, London, 1994, pp. 59-104.

[10] Champagnat P., Rest and activity in vegetative buds of trees, Ann. Sci. For. 46 Suppl. (1989) 9-26.

[11] Cluzeau C., Dupouey J.L., Courbaud B., Polyhedral representation of crown shape. A geometric tool for growth modelling, Ann. Sci. For. 52 (1995) 297-306. 
[12] Cooper A.J., Root temperature and plant growth, Research Review No. 4, Commonwealth Agricultural Bureaux, 1973, 73 pp.

[13] Courbaud B., Modélisation de la croissance en forêt irrégulière. Perspectives pour les pessières irrégulières de montagne, Rev. For. Fr. 47 (No. sp.) (1995) 173-182.

[14] Courbaud B., Process-based vs. empirical tree growth models: is light interception a better predictor of tree growth than stand basal area?, Tree Physiol., in press.

[15] De Reffye P., Houllier F., Modelling plant growth and architecture. Some recent advances and applications to agronomy and forestry, Current Sci. 73, 11 (1997) 984-992.

[16] De Reffye P., Houllier F., Blaise F., Fourcaud T., Essai sur les relations entre l'architecture d'un arbre et la grosseur de ses axes végétatifs, in: Modélisation et simulation de l'architecture des végétaux, Bouchon J., De Reffye P., Barthélémy D. (Eds.), INRA Ed., Versailles, France, Coll. Science Update, 1997, pp. 255-424.

[17] Dewar R.C., A simple model of light and water use evaluated for Pinus radiata, Tree Physiol. 17 (1997) 259-265.

[18] Doehlert D.C., Chourey P.S., Possible roles of sucrose synthase in sink function, in Bonnemain J.L., Delrot S., Lucas W.L., Dainty J. (Eds.), Recent advances in phloem transport and assimilates compartmentation, 1991, pp. 187-193.

[19] Doussan C., Pagès L., Vercambres G., Modelling of the hydraulic architecture of root systems: an integrated approach to water absorption - model description, Ann. Bot. 81 (1998) 213-223.

[20] Escobar-Gutiérrez A.J., Daudet F.A., Gaudillère J.P., Maillard P., Frossard J.S., Modelling of allocation and balance of carbon in walnut (Juglans regia L.) seedlings during heterotrophy-autotrophy transition, J. Theor. Biol. 194 (1998) 2947.

[21] Farquhar G.D., Caemmerer von S., Berry J.A., A biochemical model of photosynthetic $\mathrm{CO}_{2}$ assimilation in leaves of $\mathrm{C}_{3}$ species, Planta 149 (1980) 78-90.

[22] Fournier C., Andrieu B., A 3D architectural and process-based model of maize development, Ann. Bot. 81 (1998) 233-250.

[23] Gary C., Jones J.W., Tchamitchian M., Crop modelling in horticulture: state of the art, Scientia Horticult. 74 (1998) 320.

[24] Génard M., Pagès L., Kervella J., A carbon balance model of peach tree growth and development for studying the pruning response, Tree Physiol. 18 (1998) 351-362.

[25] Goudriaan J., Crop micrometeorology. A simulation study, Simulation monographs, Centre for Agricultural Publishing and Documentation, Wageningen, 1977.

[26] Harley P.C., Thomas R.B., Reynolds J.F., Strain B.R., Modelling photosynthesis of cotton grown in elevated $\mathrm{CO}_{2}$, Plant Cell Env. 15 (1992) 271-282.

[27] Houllier F., Leban J.M., Colin F., Linking growth modelling to timber quality assessment for Norway spruce, For. Ecol. Man. 74 (1995) 91-102.
[28] Jacquet P., INCA: Outil d'intégration spécialisé dans l'étude de l'arbre, mémoire CNAM, Clermont-Ferrand, France (1996), 120 pp. + ann.

[29] Jarvis, P.G., The interpretation of the variation in leaf water potential and stomatal conductance found in canopies in the field, Phil. Trans. R. Soc. London B 273 (1976) 593-610.

[30] Johnson I.R., Thornley J.H.M., Temperature dependence of plant and crop processes, Ann Bot. 55, 1 (1985) 1-24.

[31] Kajji A., Carbon economy in young walnut (in French), Ph.D. Thesis, University Clermont-Ferrand 2, France, 1992, $77 \mathrm{pp}$.

[32] Knowe S.A., Ahrens G.R., DeBell D.S., Comparison of diameter-distribution-prediction, stand-table-projection, and individual-tree-growth modeling approaches for young red alder plantations, For. Ecol. Manage. 98 (1997) 49-60.

[33] Korol R.L., Milner K.S., Running S.W., Testing a mechanistic model for predicting stand and tree growth, For. Sci. 42, 2 (1996) 139-153.

[34] Lacointe A., Carbon allocation among tree organs: a review of basic processes and representation, Ann. For. Sci. 57 (2000) 521-533.

[35] Lacointe A., Kajji A., Daudet F.A., Archer P., Frossard J.S., Seasonal variation of photosynthetic carbon flow rate into young walnut and its partitioning among the plant organs and functions, J. Plant Physiol. 146 (1995) 222-230.

[36] Lacointe A., Gary C., Demotes-Mainard S., Vandame M., La répartition des assimilats dans la plante: faits et hypothèse, in: Cruiziat P., Lagouarde J.P. (Eds.), Écolechercheur du département de Bioclimatologie, Tome 1 : De la plante au couvert, INRA, Département de Bioclimatologie, Thivernal-Grignon, France, 1996, 155-180.

[37] Le Dizès S., Modélisation des relations structure-fonction du noyer; application à la taille, Ph.D. Thesis, University of Orsay, France, 1998, 205 pp. + ann.

[38] Le Dizès S., Martin-Clouaire R., Jacquet P., Cruiziat P., A knowledge-based system for simulating structure-function relationships in walnut tree growth processes, in: Proceedings of Information and communication technology application in Agriculture, Wageningen, The Netherlands, 1996/06/16-19, WICC-IAC, Computers and Electronics in Agriculture, 1996, pp. 315-321.

[39] Le Dizès S., Cruiziat P., Lacointe A., Sinoquet H., Le Roux X., Balandier P., Jacquet P., A model for simulating structure-function relationships in walnut tree growth processes, Silva Fenn. 31, 3 (1997) 313-328.

[40] Le Roux X., Sinoquet H., Vandame M., Spatial distribution of leaf dry weight per area and leaf nitrogen content in relation to local radiation regime within an isolated tree crown, Tree Physiol. 19 (1999) 181-188.

[41] Le Roux X., Grand S., Dreyer E., Daudet F.A., Parameterisation and testing of a biochemically based photosynthesis model for walnut (Juglans regia L.) trees and seedlings, Tree Physiol. (1999) 481-492.

[42] Mauget J.C., Comportement comparé des bourgeons de l'année et des bourgeons latents chez le noyer (Juglans regia 
L., cv. "Franquette"). Conséquence sur la morphogénèse de l'arbre, Agronomie 4, 6 (1984) 507-515.

[43] Mauget J.C., Frizot N., Guinard J., Effect of time and position of summer pruning on the release from inhibition of the axillary buds of walnut sprouts, In: International walnut meeting, Tarragona, Spain, 1991/10, Acta Hort. 311 (1993) 210-216.

[44] Morris D.M., Kimmins J.P., Duckert D.R., The use of soil organic matter as a criterion of the relative sustainability of forest management alternatives: a modelling approach using FORECAST, For. Ecol. Manage. 94 (1997) 61-78.

[45] Norman J.M., Welles J.M., Radiative transfer in an array of canopies, Agron. J. 75 (1983) 481-488.

[46] Pagès L., Doussan C., Vercambre G., Below-ground environment and ressource acquisition. Simulation models should include plant structure and function, Ann. For. Sci. 57 (2000) 513-520.

[47] Penning de Vries F.W.T., The cost of maintenance processes in plant cells, Ann. Bot. 39 (1975) 77-92.

[48] Perttunen J., Sievänen R., Nikinmaa E., Salminen H., Saarenmaa H., Väkevä J., LIGNUM: a tree model based on simple structural units, Ann. Bot. 77 (1996) 87-98.

[49] Perttunen J., Sievänen R., Nikinmaa E., LIGNUM: a model combining the structure and the functioning of trees, Ecol. Modelling 108 (1998) 189-198.

[50] Pinkard E.A., Beadle C.L., Davidson N.J., Battaglia M., Photosynthetic light responses of Eucalyptus nitens (Deane and Maiden) Maiden to green pruning, Trees 12 (1998) 119129.

[51] Rageau R., Étude expérimentale des lois d'action de la température sur la croissance des bourgeons floraux du pêcher (Prunus persica L. Batsch) pendant la post-dormance, C. R. Acad. Agric. Fr. 68, 9 (1982) 709-718.

[52] Rauscher H.M., Isebrands J.G., Host G.E., Dickson R.E., Dickmann D.I., Crow T.R., Michael D.A., ECOPHYS: An ecophysiological growth process model for juvenile poplar, Tree Physiol. 7 (1990) 255-281.

[53] Richardson E.A., Seeley S.D., Walker D.R., A model for estimating the completion of rest for Redhaven and Elberta peach trees, Hortsci. 9, 4 (1974) 331-332.

[54] Riedacker A., Rythmes de croissance et de régénération des racines des végétaux ligneux, Ann. Sci. For. 33, 3 (1976) 109-138.
[55] Ross J.K., The radiation regime and the architecture of plant stands, The Hague: Junk W. Pubs, 1981

[56] Ruget F., Respiration de croissance et d'entretien : méthodes de mesure, comparaison des résultats, Agronomie 7 (1981) 601-610.

[57] Sievänen R., Nikinmaa E., Nygren P., Ozier-Lafontaine H., Perttunen J., Hakula H., Components of a functional-structural tree model, Ann. For. Sci. 57 (2000) 399-412.

[58] Sinoquet H., Le Roux X., Short term interactions between tree foliage and the aerial environment: An overview of modelling approaches available for tree structure-function models, Ann. For. Sci. 57 (2000) 477-496.

[59] Snowdon P., Woollons R.C., Benson M.L., Incorporation of climatic indices into models of growth of Pinus radiata in a spacing experiment, New For. 16 (1998) 101123.

[60] Spiecker H., Mielikainen K., Kohl M., Skovsgaard J.P., Growth trends in European forests, in Spiecker H., Kohl M., Mielikainen K., Skovsgaard J.P. (Eds.), European Forest Institute, Springer-Verlag, Berlin, Heidelberg, New York, pp. 355-367.

[61] Thaler P., Pagès L., Modelling the influence of assimilate availability on root growth and architecture, Plant Soil 201 (1998) 307-320.

[62] Thornley J.H.M., Respiration, growth and maintenance in plants, Nature 227 (1970) 304-305.

[63] Thornley J.H.M., Modelling shoot-root relations: the only way forwards?, Ann. Bot. 81 (1998) 165-171.

[64] Väisänen H., Kellomäki S., Oker-Blom P., Valtonen E., Structural development of Pinus sylvestris stands with varying initial density: a preliminary model for quality of sawn timber as affected by silvicultural measures, Scand. J. For. Res. 4 (1989) 223-238.

[65] Varlet Grancher C., Variation et estimation de l'énergie d'origine solaire reçue sur des plans d'inclinaison et d'azimut variables, Ann. Agron. 26, 3 (1975) 245-264.

[66] Walsh J.W.T., The science of daylight, Mac Donald, London, 1961, $291 \mathrm{pp}$.

[67] Wang Y.P., Jarvis P.G., Description and validation of an array model MAESTRO, Agric. For. Meteorol. 51 (1990) $257-280$. 